\title{
Rescue the Perishing: A New Approach to Supplemental Instruction
}

\section{Calvin B. Peters}

University of Rhode Island

"I don't understand why I did so poorly. I read the books, I came to every class, I took notes, I came to the help sessions, I studied for hours. When I got to the test, I just couldn't do it. What can I do?" This is the question that tries an instructor's soul because the kneejerk response-"Try harder"-is ineffective, and because it arouses the convenient but unfounded suspicion that the admissions office has finally hit bottom.

If the conversation continues, the question is even more trying. Oh, we might mumble something about more regular study; that, it seems, is our favorite bit of advice. Or, we might suggest that the befuddled seek remedial help at the Learning Assistance Center. This, at least, gets them out of our offices and into someone else's across campus. None of this is very satisfying. We've never been to the Learning Assistance Center, so we don't know what goes on there, and we do know that regular study isn't the panacea we pretend it to be. We are caught in a dilemma of our own device. We've worked diligently to be sure that our courses require students to move to the application of ideas and beyond. And we know we've succeeded. Our students can't do what we ask, and there doesn't seem to be anything we can say or do to help.

Of course, the dilemma can be resolved through a series of machinations. On exams, we can conspire with students to transform legitimate application questions into memory 
items by giving away the answers. We can contort our grading schemes to award A's and B's to students who couldn't apply a memorized principle to a new situation if their lives depended on it. We can give outrageously low grades to scores of students and tout that as a sign of a truly college-level course. But none of that is very satisfying either.

What would be satisfying is a scheme that would allow students to transform their abilities to read texts, to take notes, to study, and to take tests so that they-many of them-could learn to apply the principles and concepts of a discipline to new situations and problems. I believe such a scheme exists. It requires work on the part of the instructor, but, in the end, it promises to help students learn to think.

\section{THE IDEA OF SUPPLEMENTAL INSTRUCTION}

There are a goodly number of ideas that I wish I could claim as my own. This is one of them. But like evolution by natural selection and the Slinky, this idea is not mine. I found it, after considerable prompting by the Instructional Development Program at URI, in The Journal of Higher Education (1983). There, in an article entitled "Breaking the Attrition Cycle," is outlined a program of "supplemental instruction . . . designed to assist students in mastering course concepts and, at the same time, to increase student competency in reading, reasoning, and study skills" (p. 81). A perusal of the article reveals an operation in which "specialists" (often advanced undergraduates) attend "high-risk courses," take notes and complete assignments prior to conducting "three or four, fifty minute supplemental instruction sessions" each week. In these sessions, the "specialists" concentrate on modeling appropriate "thinking and languaging behavior" (p. 81), and on the use of the materials of the subject discipline as the vehicle for academic skills instruction.

No tortuous logic is required to see that the supplemental instruction program might offer a satisfying way out of the "good courses--befuddled students-no way to help" dilemma described above. Of course, supplemental instruction is well known to many instructional development personnel, thanks in part to a widely publicized endorsement by the Department of Education. There is nothing wrong in that; it is a good idea 
that deserves praise.

The celebration of supplemental instruction has, however, drawn attention not to the underlying principles that make the idea a good one, but rather to the structure described in the $J H E$. The effect of this structural emphasis has, I think, institutionalized a single way of thinking about the idea. Now, when supplemental instruction is mentioned, it is discussed as a particular program, organized and implemented in a particular way.

For some campuses, this emphasis on the programmatic aspects of supplemental instruction is not a problem. They have the resources necessary to duplicate the now standard, specialistcentered program of supplemental instruction. Unfortunately, for most of us-both faculty and instructional development personnel-supplemental instruction in its full-blown, programmatic form is simply not feasible. We don't have the resources, we don't have specialists, nor do we have any hope of acquiring them. A program of supplemental instruction is for us only a hope, that, like so many in the academic world, begins with "If only we had more. .."

All of this is true only so long as supplemental instruction is conceived as a program rather than an idea. What makes supplemental instruction work is not the particular structure in which it first appeared, but rather the principle of using materials from your course to provide your students organized practice in the academic skills most necessary for them to succeed in your grading system. Obviously, if it is to be employed, this principle requires some structure, but it cioesn't have to depend on specialists, and it doesn't have to be expensive. So, for those of you who find the idea of supplemental instruction attractive, but who find the program prohibitively costly and complex, what follows is an alternative-in short, supplemental instruction on the cheap.

\section{PRELIMINARY CONSIDERATIONS}

Before beginning even a cheap supplemental instruction program, you should first be sure that your course requires students to do more than memorize the texts and the wisdom dispensed in your lectures. This is often not easy to do. Old habits are hard to break, and the tradition of asking students 
to recapitulate your own comparisons and contrasts, your own explanations, and your own projections of the consequences of various theories is one of the hardest. If you want students to do a better job in memorizing what you and designated authors have said, don't bother with supplemental instruction; just be clearer about what it is that you want them to know. But if you want your students to move beyond memorization, and you have examinations and assignments that require them to do so, think seriously about supplemental instruction.

Second, you should be sure you know what you are getting into. Supplemental instruction is not a fancy substitute for standard "help sessions." It is not designed merely to review lectures, to answer questions, and to clarify fuzzy thinking. It is, rather, designed to provide instruction in academic skills (e.g., text-reading, note-taking, studying, examination-taking) in a context tailor-made for a specific course. Although "standard" review may constitute a part of supplemental instruction sessions, the development of skills should remain paramount.

In the specialist-centered, deluxe program of supplemental instruction, this distinction between review and skills development must be maintained by the specialist responsible for the conduct of the sessions. If you're doing supplemental instruction on the cheap, you'll be the specialist. This may, in fact, be an improvement. Who better to model academic skills on course material? Who better to create realistic practice settings? Who better to see to it that the session focus on skills and application not recitation and memory?

Once you've sorted through your course and decided that supplemental instruction is for you (and this is not a decision that should be made lightly because there is considerable work connected to it), you'll need to focus your efforts on specific skills. The rubric of "academic skills" is not sufficiently narrow to allow you to construct coherent, manageable sessions. Besides, if you advertise to your students the sessions you've planned (and you should; see below), you'll want to be able to say things like, "Tuesday we'll work on note-taking; Thursday we'll give you some practice in getting ready to take an exam; and next Tuesday we'll actually take a practice examination." That specificity is more attractive to students than the generic skills approach.

So, how can you identify particular skills on which to focus 
your supplemental instruction sessions? The best way to do this is to work your way through what you expect your students to do. Most of us expect them to read books, to listen to lectures, and to take examinations after preparing for them. If you concentrate on the text-reading, note-taking, studying, and examination-taking skills necessary for those activities, you won't go wrong. Remember, some of the more common comments from students (usually made with an inflection that can't be transcribed) are: "I don't understand the reading; the book is too hard"; "I can't follow you when you lecture"; "I study the wrong things"; "I can't take the kind of tests you give; they don't test what I know."

This-sessions devoted to particular skills-is another one of the differences between deluxe supplemental instruction and the on-the-cheap version. When you can't have three or four sessions a week (and if you're the one doing them, you probably can't), you need to plan to spend your time most effectively. By focusing entire sessions on particular skills, you can pay some concentrated attention to the skills that are most important for students' success in your course.

\section{TIMING AND STRUCTURE}

The timing of the introduction and conduct of supplemental instruction sessions is crucial to their success. There is an almost irresistible urge to wait to see if your students can, by some miracle, without any assistance from you, learn to apply the principles of your discipline to new situations. All of us believe that examinations are motivators. If students do well on them, there's nothing extra to do; if they do poorly on them, of course, they'll be especially motivated to seek help. Don't believe it, even for a minute. By the time of the first examination, even if it's only three weeks into the course, it's too late to change students' habits. They've settled in. They're doing what they'll continue to do for the rest of the semester, despite the eloquence of your admonitions.

If you want your supplemental instruction to be most effective, you'll need to start it as near to the beginning of the semester as possible. Each student in your course has a set of study skills. Despite your suspicions about the admission office, that's how they got into college. If you let them unpack those 
skills and begin to use them, all your warnings about how different your course is from the others they've had will fall on deaf ears. By scheduling your set of supplemental instruction sessions in the first two weeks of the semester, you can give substance to your claims that there is something more than memory to be done in your course. Do them early. The first exam will tell students if what you suggest is productive. If it is, they'll keep doing it. If it isn't, then, well, maybe they can go back to memorizing without any risk.

Let me say a word about attendance. If these sessions are advertised-in the syllabus and orally in class-you'll find that attendance will be much higher if the sessions are held early, before the first exam. Students perceive them as a normal (and almost expected) part of the course. There is none of the stigma that often attaches to workshops, help sessions, and the like conducted because "a lot of you didn't do well on the first exam." All of this works together to convince them that you might be serious when you say that "you can't succeed in this course by memorizing."

More important than advertising are the sessions themselves. What must be done to ensure that they are productive and interesting? There are, I think, three general principles that can be easily translated into meaningful workshop sessions. The first is the most important. The workshops, as the name implies, should be active. Don't let your students just sit there and take notes on what you say, even if the skill you plan to cover is note-taking. What you hope they take away from the workshop is a set of new ways of doing things, not a list of things that would be good to do. If they are going to learn how to study, how to take examinations, how to take notes, how to read texts, they are going to have to engage in those activities. Lists of principles are fine. In fact, you should probably try to develop some as summaries to be distributed at the end of the workshops. But, by themselves, the principles, no matter how cogent, won't do. They must be derived from activity if they are to do the job.

Of course, just any activity won't do. This brings up the second principle. Your workshops should simulate the actual conditions under which your students labor. Don't give them a list of principles of text-reading; give them a list of principles that apply to the specific texts assigned in your course. Don't 
engage them in note-taking from a packaged lecture; engage them in note-taking from a video tape of a lecture you've just given in class. This is the heart of the idea. Your workshops are designed to encourage the development in students of study skills that will allow them to succeed in your course. Those skills are best developed through the active use of the materials from your course. Use your texts, use your lectures, use your examinations. If you don't, give up your workshops altogether-they already hold workshops using generic material in the Learning Assistance Center.

There is no reason to go to the trouble to conduct workshops if you don't give your students a chance to put to work the skills you've focused on. This is the third principle: your workshops should give students plenty of opportunities to practice on real, live course material the skills they are developing. In your sessions, have them read and re-read the texts you've assigned. Help them to apply the principles to the material. Have them study for an examination. Give them the exam. Review it with them. Give them a chance to re-study. Give them a comparable exam, and so on. Whatever you do, give your students an opportunity to practive what you have been preaching.

\section{A SAMPLE SESSION}

Perhaps an illustration will help make clear just how these principles can be put into practice. I usually conduct four workshops for my students sometime in the first two weeks of the semester. The most important is, I believe, the one devoted to studying. Even with the best notes in the world, a clear idea of the reading, and freshly honed test-taking skills, a student who has no idea of how to put those things together in a meaningful way is simply not going to succeed.

My studying workshop is usually the third in the series, and as such it follows the format established by the first two. The students come expecting to do some studying. And that is precisely what I ask them to do. Using the same excerpt from their text that I used in the reading workshop, I ask them to take five or ten minutes to study the material. The realism of the situation is heightened by the fact that at the conclusion of their study time I tell them that there will be a short, three 
question test. And away they go. I've reproduced the excerpt (Freud, 1961) below, and it might be fun for you to duplicate the exercise as you read this article.

Our enquiry concerning happiness has not so far taught us much that is not already common knowledge. And even if we proceed from it to the problem of why it is so hard for men to be happy, there seems no greater prospect of learning anything new. We have given the answer already by pointing to three sources from which our suffering comes: the superior power of nature, the feebleness of our own bodies and the inadequacy of the regulations which adjust the mutual relationships of human beings in the family, the state and society. In regard to the first two sources, our judgement cannot hesitate long. It forces us to acknowledge those sources of suffering and to submit to the inevitable. We shall never completely master nature; and our bodily organism, itself a part of that nature, will always remain a transient structure with a limited capacity for adaptation and achievement. This recognition does not have a paralyzing effect. On the contrary, it points the direction for our activity. If we cannot remove all suffering, we can remove some, and we can mitigate some: the experience of many thousands of years has convinced us of that. As regards the third source, the social source of suffering, our attitude is a different one. We do not admit it at all; we cannot see why the regulations made by ourselves should not, on the contrary, be a protection and benefit for every one of us. And yet, when we consider how unsuccessful we have been in precisely this field of prevention of suffering, a suspicion dawns on us that here, too, a piece of unconquerable nature may lie behind-this time a piece of our own psychical constitution.

When we start considering this possibility, we come upon a contention which is so astonishing that we must dwell upon it. This contention holds that what we call our civilization is largely responsible for our misery, and that we should be much happier if we gave it up and returned to primitive conditions. I call this contention astonishing because, in whatever way we may define the concept of civilization, it is a certain fact that all the things with which we seek to protect ourselves against the threats that emanate from the sources of suffering are part of that very civilization.

Are you ready for the examination? Most of them, as is probably the case with those of you who are playing along at home, say they think so, but they are a little nervous because they don't know exactly what is going to be on the test. It's a perfect simulation of the situation that obtains when the first real exam is given in the course. Without further ado, the test. 


\section{Exam I}

1. What are the three sources from which human suffering comes?

2. Which of the sources of human suffering seems most likely to be controlled by human efforts?

3. In which condition, primitive or civilized, does Freud believe we would be happier?

So, how did you do? Was the test hard? Easy? As you might guess, after I review the answers most students discover they did well on this examination. It is precisely the kind of thing they know how to prepare for. The questions are drawn directly from the reading, and they require nothing more advanced than memory. The students know that. With a little prompting, they will tell me that the test was "easy because it was all right there and they just had to memorize it."

At this point, when they are flushed with success, I remind them that for my course memorization is not the most important skill. With that as the only hint, I tell them that they've got five more minutes to study for another examination with three new questions of a different kind. In they plunge; they still know what to do. Take the same five minutes to get ready for Exam II.

\section{Exam II}

1. Freud believes that some of our suffering is inevitable. Explain the logic behind Freud's belief.

2. The "human source" of suffering, Freud says, cannot be "admitted at all." What is the meaning of this claim?

3. Freud claims that we would be happier if we "abandoned" civilization. Explain the reasons behind this "astonishing" claim.

They don't do quite so well on this examination, but still the performance of the group is good. Of course, they say this examination is harder than the first one, and they suspect that it is this sort of question that will appear on the first real exam in a week or two. When I ask them what they had to do to prepare for this test, they say things like "you really had to know it" or "you couldn't just memorize, you had to understand it." They aren't at a loss. They know how to prepare for this sort of question. They may not like it, but they know how 
to do it.

This is the critical point in the workshop. Exam II is probably harder than Exam I, but it does not require students to do anything other than memorize in order to succeed. They now commit to memory connections that Freud makes in the text (or that most likely would be made by a lecturer in class) instead of isolated bits of information. Nonetheless, they memorize. What they must memorize differs; the intellectual skill remains the same. The point is not lost on them. The two exams test the same content and the same skill--memory. Exam II may require students to memorize more important material, but the answers to the questions can be supplied by rote.

Again, that's not the skill I am interested in my students developing. So, you've guessed it, I tell them that they've got a few more minutes and then there will be yet another exam, over the same material, with three questions of still another type. Now they've run out of ideas and patience (as you must be). "Just give us the test," they say. Okay, here goes.

\section{Exam III}

1. Advances in medicine promise to relieve pain and suffering and to prolong human life. Explain how Freud would react to a statement that these sorts of advances promise to eliminate the suffering that comes "from the feebleness of our own bodies."

2. A claim is made that society, if it is just, with equal opportunity for all, can produce satisfied and happy individuals. How would Freud respond to such a claim?

3. A sociologist claims that because of modern conveniences and technological advances, citizens in the industrial world are better off than memiers of "primitive" civilizations. How would Freud respond to this idea?

What is different about these questions? They aren't in the reading, you can't memorize the answers, and ultimately, they say, you can't study for them. But, of course, what they mean is that there is nothing to memorize, and because memorizing is studying, well, there's no way to prepare. By now they have figured out that the sort of questions that I intend to ask is the kind on Exam III. They also have some idea of what won't be productive when they sit down to study. And that's 
not bad, especially because they have discovered it in an active way in a situation enough like their real classroom experiences to be meaningful.

I close the session by trying to crystalize what steps I think are useful in studying Freud. By themselves, I don't believe these study hints are particularly useful. Placed in the context of this workshop, illustrated by a little modeling on my part and a little practice on theirs, they seem to work reasonably well. You can judge for yourself.

\section{HINTS ON STUDYING FREUD}

1. Keep in mind the instructional objectives (what you are supposed to know or be able to do). The best reference for you is your syllabus (pages 3 and 4 ). In it I have described the kinds of things you will be able to do on the examinations, and I have provided some examples.

2. Memorizing massive amounts of material will not help you on the examinations. There will be very few questions designed to test your memory of definitions, etc. Most of the questions will ask you to recognize examples of concepts and to use concepts to interpret new situations.

3. As you read Freud engage him in a dialogue. Ask him questions about things you disagree with; answer them for him (he can't due to his demise-his body caused him suffering). Write down your conversations.

4. Keep close track of examples that Freud uses or that I use in class. Try to construct your own examples based on those that Freud and I use.

5. Make lists of the important concepts. Keep track of how the concepts are connected to one another.

6. Spend your reading time asking questions. What does this mean? How would Freud respond to such and such a claim?

7. Keep in mind that your job is to learn how to think like Freud. You don't need to memorize what Freud thought, you need to be able to apply what he thought to situations he didn't think about.

By using the principles listed above and the outlines of the studying workshop as a rough blueprint, it should be relatively easy to design productive workshop sessions. If the "modeling" mentioned in the discussion of deluxe supplemental instruction is added to them, you have the makings of a top-notch, on-thecheap program. They try, you model. They try again, you discuss principles. You model, they practice. It will work like a charm. 


\section{CONCLUDING THOUGHTS}

Speaking of working, does all of this (any of this?) work? It's hard to tell. The results reported in the $J H E$ indicate that the deluxe version works, and spectacularly at that. There are no comparable figures for the on-the-cheap model, but, if my own experience is any guide, it's safe to say that the cheap version works, if not spectacularly, very well. Students report overwhelmingly that the sessions are beneficial, and their behavior is consistent with that claim. They sample sessions, and continue to attend. They even bring their friends.

Because of this effectiveness, there is, I think, a temptation to drop the "supplemental" from this sort of instruction and to integrate it into regular class sessions. I have resisted doing this for two reasons. First, not surprisingly, is the issue of coverage. The four sessions I conduct last a cumulative six hours. Further, though the workshops do use course material, and therefore do provide some review of course content, they are expressly devoted to skill development. If that time is removed from the class sessions that remain after those several periods devoted to examinations are subtracted, I would have to choose to drop course material in order to develop skills. Happily, when the sessions are supplemental, that is a choice that doesn't have to be made.

Second, I believe the "supplemental" character of the workshops has a salutary effect on students' perception of the course and what they need to do in order to succeed. It is clear to them from the workshops that the course demands something different. It is also clear that to them their instructor recognizes his reponsiblity to provide students the support they require. The fact that I (not some "third-party" specialist) conduct these supplemental workshops demonstrates in a way that ample office hours do not that I am willing to work outside of class to help them develop the skills they need to succeed in class. This message makes its mark on them.

If you don't find this apology for "supplementalism" persuasive, devote some class time to course-content-based skill instruction. After all, it's the idea not the structure that's important. 


\section{REFERENCES}

Blanc, R. A., DeBuhr, L. E. \& Martin, D. C. (1983). Breaking the attrition cycle. Journal of Higher Education, 54, 80-89.

Freud, Sigmund (1961). Civilization and its discontents. New York: Norton. 